\title{
Reverse-flow reactor for a selective oxidation process
}

\author{
R. Quinta Ferreira ${ }^{\mathrm{a}, *}$, C. Almeida Costa ${ }^{\mathrm{a}}, \mathrm{S}$. Masetti ${ }^{\mathrm{b}}$ \\ ${ }^{a}$ Department of Chemical Engineering, University of Coimbra, Portugal \\ ${ }^{\mathrm{b}}$ Department of Industrial Chemistry and Materials, University of Bologna, Italy
}

\begin{abstract}
The simulation of a reverse-flow operation of a fixed-bed catalytic reactor, where the highly exothermal partial oxidation of $o$-xylene to phthalic anhydride is processed, is accomplished by using a heterogeneous one-dimensional model, which accounts for mass transport by diffusion and convection inside large-pore catalytic particles. The dynamic behaviour of the reactor is analysed by varying the inlet conditions and the switching period. This work points out the benefits that can arise from the use of the reverse-flow operation, namely the decrease of the hot-spot temperature and the more favourable temperature distribution along the bed. In spite of the lower temperature profiles, the final conversion, as well as selectivity and yield of phthalic anhydride are not significantly affected. The results predicted by the heterogeneous model with intraparticle convection and diffusion, $\mathrm{HT}_{d c}$ model, are compared with those obtained when diffusion is the only transport mechanism inside the catalyst, $\mathrm{HT}_{d}$ model. A comparison with the simple pseudo-homogeneous model, PH, is also achieved. (C) 1999 Elsevier Science Ltd. All rights reserved.
\end{abstract}

Keywords: Reverse-flow operation; Unsteady-state catalytic process; Non-adiabatic fixed-bed reactor; Partial oxidation; Mathematical modelling; Intraparticle convection

\section{Introduction}

Since the beginning of the 1960s, the advantages of forced unsteady-state operation (FUSO) over conventional steady-state regime of catalytic fixed-bed reactors have been highlighted in the literature. In transient conditions, the combination of the dynamic properties of the catalyst, at a microscale level and the dynamic properties of the reactor, at a macroscale level, make it possible to obtain more favourable concentration and temperature profiles for the catalytic process. Among the several techniques of FUSO, special attention has been devoted to the periodic alternation of feed introduction between the ends of the packed-bed catalytic reactor, denominated by reverse-flow operation (RFO), whose advantages were enumerated by Matros (1990).

During the last decade, RFO has been subjected to detailed study on both theoretical and functional aspects. It is now being used for industrial applications such as the catalytic incineration of volatile organic compounds for purification of industrial exhaust gases, the oxidation of $\mathrm{SO}_{2}$ for sulfuric acid and the selective reduction of $\mathrm{NO}_{x}$ by ammonia. Some other processes are in development,

\footnotetext{
* Corresponding author.
}

such as the methane oxidation and the methanol synthesis. A recent and excellent review of Matros and Bunimovich (1996) gives a detailed overview of the advances that have been made in reverse-flow operation.

The scope of this paper is to prove that reverse-flow operation can also be beneficial in non-adiabatic fixedbed reactors with strongly exothermal reactions. The partial oxidation of $o$-xylene to phthalic anhydride is used here as a case study. The effect of intraparticle convective mass flux, which can be taken into account when large-pore catalysts are used, is also analysed. In previous studies, the effect of the additional convective mechanism inside the catalyst particles on the behaviour of fixed-bed reactors was examined, for both steady state and dynamic operation (Rodrigues and Quinta Ferreira, 1990; Quinta Ferreira et al., 1992a, 1992b, 1996; Almeida Costa et al., 1994).

\section{Mathematical models}

Fig. 1a represents a sketch of the flow reversal reactor, where the feed mixture is introduced alternatively through entrances E1 and E2.

The first kinetic scheme used in this work for the of $o$-xylene partial oxidation in a $\mathrm{V}_{2} \mathrm{O}_{5}$ catalyst 


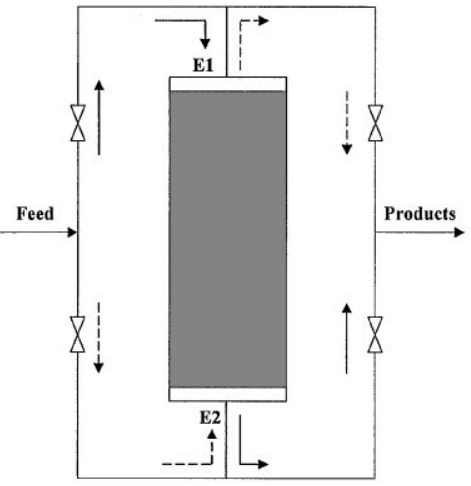

(a)
First kinetic scheme:

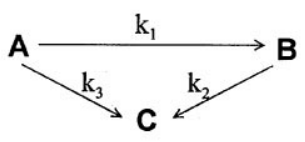

$\underline{\text { Second kinetic scheme: }}$

$\mathrm{k}_{1}$

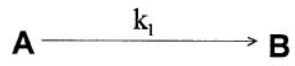

(b)
Fig. 1. (a) Sketch of the reverse-flow reactor; (b) kinetic schemes.

(Froment, 1967) is represented in Fig. 1b, where A stands for $o$-xylene, $\mathrm{B}$ for phthalic anhydride and $\mathrm{C}$ for $\mathrm{CO}_{x}$ that result from total combustion of $\mathrm{A}$ and $\mathrm{B}$. In this reaction, air is used in excessively, as the $o$-xylene mole fraction must be kept in very low percentages to stay under the explosion limits. Therefore, the rate equation for each step $j(j=1,2,3)$ is of pseudo-first order in the partial pressure of the corresponding reactant $i(i=\mathrm{A}$ for $j=1,3$ and $i=\mathrm{B}$ for $j=2$ ):

$r_{j}=k_{j} p_{i} p_{\mathrm{O}_{2}}$.

For each step, the kinetic constant is expressed by

$k_{j}=\exp \left(a_{j}-\frac{E_{j}}{R T}\right)$.

The kinetic parameters for this system of multiple reactions are indicated in Table 1 . In a second approach, only the single irreversible reaction $\mathrm{A} \rightarrow \mathrm{B}$ of the previous scheme is considered (Froment and Bischoff, 1979).

The cyclic steady-state of a fixed-bed reactor with flow reversal is obtained through dynamic simulation. The integration of the transient model equations over a large number of flow reversals usually requires high computing times.

A great variety of dynamic mathematical models, with different levels of complexity have been used in the literature to simulate the behaviour of these novel reactors.
The first studies on reverse flow reactors have been based on simplified one-dimensional models. Gawdzik and Rakowski (1988) and Gosiewski and Sztaba (1990) used simple pseudo-homogeneous models for the modelling and simulation of reverse-flow catalytic reactors, neglecting the transient terms in the mass balances. Eingenberger and Nieken (1988) used a simple pseudo-homogeneous model with axial dispersion applied to a catalytic combustion, assuming also pseudo-steady state for the continuity equations. A full transient pseudo-homogeneous model was used by Thullie and Burghardt (1990) for the simulation of a methanol synthesis reactor. According to Matros (1990), a completely transient one-dimensional heterogeneous model, accounting for internal and external diffusional limitations is preferable for the modelling and simulation of reverseflow reactors. For a first-order exothermic reaction, Rehacek et al. (1992) employed a heterogeneous model that included axial dispersion in the gas phase, axial conduction in both solid and gas phases and cooling from the wall. Van den Bussche et al. (1993) established a fully transient heterogeneous one-dimensional model for the methanol synthesis, accounting for axial heat and in the solid phase and for pressure drop across the bed. The authors compare the performance of this sophisticated model to the results obtained when mass and energy capacity terms for the gas phase and mass capacity for the solid-phase continuity equations are not accounted for in the model. Snyder and Subramanian (1993) used a heterogeneous one-dimensional model for the reversible catalytic oxidation of sulphur dioxide to sulphur trioxide in an adiabatic reverse-flow reactor. The authors used a pseudo-steady-state effectiveness factor for the catalyst particle, but they took into account the pressure drop in the reactor, the density variations in the gasphase reaction mixture and also the change of transport properties with temperature and flow. Starting from a detailed two-phase model that accounts for axial conduction and dispersion, Nieken et al. (1995) present some simplifications that can be used to calculate fast and accurate approximations of the pseudo-steady-state profiles.

In this work, a heterogeneous one-dimensional model is used, with the following assumptions:

- the gases behave ideally at the operating conditions considered;

Table 1

Kinetic and thermodynamic parameters

\begin{tabular}{lll}
\hline Pre-exponential factor & Activation energy & Enthalpy \\
\hline$a_{1}=19.837$ & $E_{1}=27000 \mathrm{cal} / \mathrm{mol}$ & $\left(-\Delta H_{1}\right)=307000 \mathrm{cal} / \mathrm{mol}$ \\
$a_{2}=20.860$ & $E_{2}=31400 \mathrm{cal} / \mathrm{mol}$ & $\left(-\Delta H_{2}\right)=783000 \mathrm{cal} / \mathrm{mol}$ \\
$a_{3}=18.970$ & $E_{3}=28600 \mathrm{cal} / \mathrm{mol}$ & $\left(-\Delta H_{3}\right)=1090000 \mathrm{cal} / \mathrm{mol}$ \\
\hline
\end{tabular}


Table 2

Operating conditions, bed and catalyst properties

\begin{tabular}{|c|c|c|}
\hline Operating conditions & Bed characteristics & Catalyst properties \\
\hline $\begin{array}{l}P=1 \mathrm{~atm} \\
P_{\mathrm{O}_{2}}^{0}=0.208 \mathrm{~atm} \\
u_{0}(\mathrm{PTN})=1 \mathrm{~m} / \mathrm{s}\end{array}$ & $\begin{array}{l}L=3 \mathrm{~m} \\
R_{0}=0.0127 \mathrm{~m} \\
\varepsilon=0.42 \\
\rho_{b}=1300 \mathrm{~kg} / \mathrm{m}^{3}\end{array}$ & $\begin{array}{l}d_{p}=0.008 \mathrm{~m} \\
a_{p}=750 \mathrm{~m}^{-1} \\
\varepsilon_{p}=0.725 \\
\tau_{p}=7 \\
S_{\mathrm{BET}}=1000 \mathrm{~m}^{2} / \mathrm{g} \\
r_{m}=6.47 \times 10^{-7} \mathrm{~m} \\
\rho_{s} c_{p s}=515500 \mathrm{cal} / \mathrm{m}^{3} \mathrm{~K}\end{array}$ \\
\hline
\end{tabular}

- axial mass dispersion is characterised by an effective dispersion coefficient and axial heat conduction in the gas and solid phases are described by effective conductivity terms;

- the fluid properties depend on temperature;

- intraparticle temperature gradients are insignificant;

- intraparticle concentration profiles develop rapidly in relation to pellet temperature transients;

- mass transport inside the catalyst pellets takes place by diffusion and convection.

The operating conditions and bed and catalyst properties are indicated in Table 2. For the heterogeneous model that considers intraparticular convection and diffusion, $\mathrm{HT}_{d c}$ model, the dimensionless equations are written in Tables 3 and 4, for the complete and simplified kinetic schemes, respectively. When diffusion is the only intraparticular transport taken into account, $\lambda_{m}$ will be set equal to zero $\left(\lambda_{m}=0\right)$ in Eq. (4) of Table 3 and Eq. (12) of Table 4, and the corresponding model is denominated $\mathrm{HT}_{d}$.

As the pseudo-steady-state approach was assumed for the intraparticle concentration profiles, the accumulation terms in Eq. (4) of Table 3 and Eq. (12) of Table 4 are null. In such circumstances, the last can be solved analytically and the same happens to Eq. (4) of Table 3, if the effective diffusivities of species $\mathrm{A}$ and $\mathrm{B}$ are assumed equal. The global behaviour of the catalyst pellet is then characterised by the isothermal effectiveness factors obtained after the integration of the intraparticle concentration profiles.

For the first kinetic scheme, the effectiveness factor of reactions (1) and (3) are given by

$\eta_{1}=\eta_{3}=\frac{\frac{1}{\delta_{1}}-\frac{1}{\delta_{2}}}{\operatorname{coth} \delta_{1}-\operatorname{coth} \delta_{2}}$

with

$\delta_{1,2}=\frac{\lambda_{m}}{2} \pm \sqrt{\frac{\lambda_{m}^{2}}{4}+\Phi_{1, s}^{2}\left(1+S_{3}\right)}$.

\section{Table 3}

Model equations for the heterogeneous one-dimensional model with diffusion and convection inside the catalyst particles, $\mathrm{HT}_{d c}-$ multiple first-order irreversible reactions

Fluid phase

Mass balance to chemical species $i$ :

$\frac{\partial f_{i, b}}{\partial t^{*}}=-\alpha_{1} \frac{\partial f_{i, b}}{\partial z^{*}}+\frac{1}{P e_{a m}} \frac{\partial^{2} f_{i, b}}{\partial z^{* 2}}-\alpha_{2} N_{f}\left[f_{i, b}-f_{i, s}\right]-\frac{\tau}{L} f_{i, b} \frac{\partial u}{\partial \theta_{b}} \frac{\partial \theta_{b}}{\partial z^{*}}$

Thermal balance:

$$
\begin{aligned}
\frac{\partial \theta_{b}}{\partial t^{*}}= & -\alpha_{1} \frac{\partial \theta_{b}}{\partial z^{*}}+\alpha_{3} \frac{1}{P e_{a h}^{f}} \frac{\partial^{2} \theta_{b}}{\partial z^{* 2}}+\alpha_{4} N_{f h}\left[\theta_{s}-\theta_{b}\right] \\
& -\alpha_{5} N_{w h}\left[\theta_{b}-\theta_{w}\right]
\end{aligned}
$$

Fluid/particle interface

Thermal balance:

$$
\begin{aligned}
\frac{\partial \theta_{s}}{\partial t^{*}}= & \frac{\tau}{\tau_{h}}\left\{\sum_{j=1 l>3} v_{i j} \eta_{j} D a_{j} B_{j} \theta_{s} \exp \left[-\gamma_{j}\left(\frac{1}{\theta_{s}}-1\right)\right] f_{i, s}\right. \\
& \left.-\alpha_{6} N_{f h}\left[\theta_{s}-\theta_{b}\right]+\frac{1}{P e_{a h}^{s}} \frac{\partial^{2} \theta_{s}}{\partial z *^{2}}\right\}
\end{aligned}
$$

Catalyst particle

Mass balance

$\frac{\partial f_{A, p}}{\partial t^{*}}=\frac{1}{4} N_{d}\left\{\alpha_{7} \frac{\partial^{2} f_{A, p}}{\partial r_{p}^{* 2}}-2 \lambda_{m} \frac{\partial f_{A, p}}{\partial r_{p}^{*}}-4 \alpha_{7} \Phi_{s, 1}^{2}\left(1+S_{3}\right) f_{A, p}\right\}$

$\frac{\partial f_{B, p}}{\partial t^{*}}=\frac{1}{4} N_{d}\left\{\alpha_{7} \frac{\partial^{2} f_{B, p}}{\partial r_{p}^{* 2}}-2 \lambda_{m} \frac{\partial f_{B, p}}{\partial r_{p}^{*}}-4 \alpha_{7} \Phi_{s, 1}^{2}\left(f_{A, p}-S_{2} f_{B, p}\right)\right\}$

Initial conditions, $t^{*}=0, z^{*} \geqslant 0$ :

$$
\begin{aligned}
f_{A, b}\left(0, z^{*}\right)= & f_{B, b}\left(0, z^{*}\right)=0 ; \quad \theta_{b}\left(0, z^{*}\right)=\theta_{s}\left(0, z^{*}\right)=\theta_{w} ; \\
& f_{A, p}\left(0, z^{*}, r_{p}^{*}\right)=f_{B, p}\left(0, z^{*}, r_{p}^{*}\right)=0
\end{aligned}
$$

Boundary conditions, $t^{*}>0$ :

$$
\begin{gathered}
z^{*}=0: \quad f_{b}=1+\left.\frac{1}{P e_{a m}} \frac{\partial f_{b}}{\partial z^{*}}\right|_{z^{*}=0} ; \quad \theta_{b}=1+\left.\frac{1}{P e_{a h}^{f}} \frac{\partial \theta_{b}}{\partial z^{*}}\right|_{z^{*}=0} ; \\
\left.\frac{\partial \theta_{s}}{\partial z^{*}}\right|_{z^{*}=0}=0 \\
z^{*}=1:\left.\frac{\partial f_{b}}{\partial z^{*}}\right|_{z^{*}=1}=\left.\frac{\partial \theta_{b}}{\partial z^{*}}\right|_{z^{*}=1}=\left.\frac{\partial \theta_{s}}{\partial z^{*}}\right|_{z^{*}=1}=0 \\
r_{p}^{*}=0, r_{p}^{*}=1, \forall z^{*}: \alpha_{8} B i_{m}\left[f_{b}-f_{s}\right]=\eta \Phi_{s}^{2} f_{s}
\end{gathered}
$$


Table 4

Model equations for the heterogeneous one-dimensional model with diffusion and convection inside the catalyst particles, $\mathrm{HT}_{d c}$ - first order irreversible reaction

Fluid phase

Mass balance:

$\frac{\partial f_{b}}{\partial t^{*}}=-\alpha_{1} \frac{\partial f_{b}}{\partial z^{*}}+\frac{1}{P e_{a m}} \frac{\partial^{2} f_{b}}{\partial z^{* 2}}-\alpha_{2} N_{f}\left[f_{b}-f_{s}\right]-\frac{\tau}{L} f_{b} \frac{\partial u}{\partial \theta_{b}} \frac{\partial \theta_{b}}{\partial z^{*}}$

Thermal balance:

$\frac{\partial \theta_{b}}{\partial t^{*}}=-\alpha_{1} \frac{\partial \theta_{b}}{\partial z^{*}}+\alpha_{3} \frac{1}{P e_{a h}^{f}} \frac{\partial^{2} \theta_{b}}{\partial z^{* 2}}+\alpha_{4} N_{f h}\left[\theta_{s}-\theta_{b}\right]-\alpha_{5} N_{w h}\left[\theta_{b}-\theta_{w}\right](10)$

Fluid/particle interface

Thermal balance:

$\frac{\partial \theta_{s}}{\partial t^{*}}=\frac{\tau}{\tau_{h}}\left\{\theta_{s} \eta D a B \exp \left[-\gamma\left(\frac{1}{\theta_{s}}-1\right)\right] f_{s}-\alpha_{6} N_{f h}\left[\theta_{s}-\theta_{b}\right]\right.$

$$
\left.+\frac{1}{P e_{a h}^{s}} \frac{\partial^{2} \theta_{s}}{\partial z^{* 2}}\right\}
$$

Catalyst particle

Mass balance

$\frac{\partial f_{p}}{\partial t^{*}}=\frac{1}{4} N_{d}\left\{\alpha_{7} \frac{\partial^{2} f_{p}}{\partial r_{p}^{* 2}}-2 \lambda_{m} \frac{\partial f_{p}}{\partial r_{p}^{*}}-4 \alpha_{7} \Phi_{s}^{2} f_{p}\right\}$

Initial conditions, $t^{*}=0, z^{*} \geqslant 0$ :

$f_{b}\left(0, z^{*}\right)=0 ; \quad \theta_{b}\left(0, z^{*}\right)=\theta_{w} ; \quad \theta_{s}\left(0, z^{*}\right)=\theta_{w} ; \quad f_{p}\left(0, z^{*}, r_{p}^{*}\right)=0$

Boundary conditions, $t^{*}>0$ :

$z^{*}=0: \quad f_{b}=1+\left.\frac{1}{P e_{a m}} \frac{\partial f_{b}}{\partial z^{*}}\right|_{z^{*}=0} ; \quad \theta_{b}=1+\left.\frac{1}{P e_{a h}^{f}} \frac{\partial \theta_{b}}{\partial z^{*}}\right|_{z^{*}=0} ;$

$$
\left.\frac{\partial \theta_{s}}{\partial z^{*}}\right|_{z^{*}=0}=0
$$

$z^{*}=1:\left.\quad \frac{\partial f_{b}}{\partial z^{*}}\right|_{z^{*}=1}=\left.\frac{\partial \theta_{b}}{\partial z^{*}}\right|_{z^{*}=1}=\left.\frac{\partial \theta_{s}}{\partial z^{*}}\right|_{z^{*}=1}=0$

$r_{p}^{*}=0, r_{p}^{*}=1, \forall z^{*}: \alpha_{8} B i_{m}\left[f_{b}-f_{s}\right]=\eta \Phi_{s}^{2} f_{s}$

For reaction (2):

$\eta_{2}=\eta_{2}^{\prime}+\frac{f_{A, s}}{f_{B, s}} \frac{1}{1+S_{3}-S_{2}}\left(\eta_{2}^{\prime}-\eta_{1}\right)$,

where

$\eta_{2}^{\prime}=\frac{\frac{1}{\beta_{1}}-\frac{1}{\beta_{2}}}{\operatorname{coth} \beta_{1}-\operatorname{coth} \beta_{2}}$

and

$\beta_{1,2}=\frac{\lambda_{m}}{2} \pm \sqrt{\frac{\lambda_{m}^{2}}{4}+\Phi_{1, s}^{2} S_{2}}$
Table 5

Model equations for the pseudo-homogeneous one-dimensional model $\mathrm{PH}$ - first order irreversible reaction

Fluid phase

Mass balance:

$$
\begin{aligned}
\frac{\partial f_{b}}{\partial t^{*}}= & -\alpha_{1} \frac{\partial f_{b}}{\partial z^{*}}+\frac{1}{P e_{a m}} \frac{\partial^{2} f_{b}}{\partial z^{* 2}}-\theta_{b} D a \exp \left[-\gamma\left(\frac{1}{\theta_{b}}-1\right)\right] f_{b} \\
& -\frac{\tau}{L} f_{b} \frac{\partial u}{\partial \theta_{b}} \frac{\partial \theta_{b}}{\partial z^{*}}
\end{aligned}
$$

Thermal balance:

$$
\begin{aligned}
\frac{\partial \theta_{b}}{\partial t^{*}}= & \alpha_{9} \frac{\tau}{\tau_{h l}}\left\{-\alpha_{10} \frac{\partial \theta_{b}}{\partial z^{*}}+\frac{1}{P e_{a h}} \frac{\partial^{2} \theta_{b}}{\partial z^{* 2}}+\theta_{b} \text { Da B exp }\left[-\gamma\left(\frac{1}{\theta_{b}}-1\right)\right]\right. \\
& \left.-\alpha_{11} N_{w h}\left[\theta_{b}-\theta_{w}\right]\right\}
\end{aligned}
$$

Initial conditions, $t^{*}=0, z^{*} \geqslant 0$ :

$f_{b}\left(0, z^{*}\right)=0 ; \quad \theta_{b}\left(0, z^{*}\right)=\theta_{w}$

Boundary conditions, $t^{*}>0$ :

$z^{*}=0: \quad f_{b}=1+\left.\frac{1}{P e_{a m}} \frac{\partial f_{b}}{\partial z^{*}}\right|_{z^{*}=0} ; \quad \theta_{b}=1+\left.\frac{1}{P e_{a h} \partial z_{b}^{*}}\right|_{z^{*}=0}$

$z^{*}=1:\left.\quad \frac{\partial f_{b}}{\partial z^{*}}\right|_{z^{*}=1}=\left.\frac{\partial \theta_{b}}{\partial z^{*}}\right|_{z^{*}=1}=0$

The effectiveness factor for the irreversible first-order kinetics, is given by

$\eta=\frac{\frac{1}{\sigma_{1}}-\frac{1}{\sigma_{2}}}{\operatorname{coth} \sigma_{1}-\operatorname{coth} \sigma_{2}}$

with

$\sigma_{1,2}=\frac{\lambda_{m}}{2} \pm \sqrt{\frac{\lambda_{m}^{2}}{4}+\Phi_{s}^{2}}$

The model equations for the pseudo-homogeneous model are referred in Table 5. The differential equations are subjected to the conventional Danckwerts boundary conditions. In this work the parameters $\alpha$ 's, listed in Table 6, account for the effect of temperature on the system properties, which were calculated through the expressions described in Table 7. For the heterogeneous model the axial conduction of heat was considered separately for gas and solid phases. Therefore, the mathematical equations of the heterogeneous models (Tables 3 and 4) include the axial thermal Péclet number for the fluid phase, Eqs. (2) and (10), and the axial thermal Péclet number for the solid phase, Eqs. (3) and (11), being $P e_{a h}^{f}=2$ and $P e_{a h}^{s}=50$ (Windes et al., 1989). For the 
Table 6

Influence of temperature on the system properties

$\alpha_{1}=\frac{\tau}{\tau\left(\theta_{b}\right)}$

$\alpha_{2}=\frac{k_{f}\left(\theta_{s}\right)}{k_{f}}$

$\alpha_{3}=\frac{\rho_{f} c_{p f}}{\rho_{f}\left(\theta_{b}\right) c_{p f}\left(\theta_{b}\right)}$

$\alpha_{4}=\frac{h\left(\theta_{s}\right)}{h} \frac{\rho_{f} c_{p f}}{\rho_{f}\left(\theta_{b}\right) c_{p f}\left(\theta_{b}\right)}$

$$
\begin{aligned}
& \alpha_{5}=\frac{U\left(\theta_{b}\right)}{U} \frac{\rho_{f} c_{p f}}{\rho_{f}\left(\theta_{b}\right) c_{p f}\left(\theta_{b}\right)} \\
& \alpha_{6}=\frac{h\left(\theta_{s}\right)}{h} \\
& \alpha_{7}=\frac{D_{e}\left(\theta_{s}\right)}{D_{e}} \\
& \alpha_{8}=\frac{D_{e}}{D_{e}\left(\theta_{s}\right)} \frac{k_{f}\left(\theta_{s}\right)}{k_{f}}
\end{aligned}
$$

$$
\begin{aligned}
& \alpha_{9}=\frac{\rho c_{p}}{\rho c_{p}\left(\theta_{b}\right)} \\
& \alpha_{10}=\frac{\tau}{\tau\left(\theta_{b}\right)} \frac{\rho_{f} c_{p f}}{\rho_{f}\left(\theta_{b}\right) c_{p f}\left(\theta_{b}\right)} \\
& \alpha_{11}=\frac{U\left(\theta_{b}\right)}{U}
\end{aligned}
$$

Table 7

Fluid, catalyst and wall transport properties

Fluid properties

$\rho_{b}=353.183 / \mathrm{T}\left(\mathrm{kg} / \mathrm{m}^{3}\right)$

$c_{p f}=238.3+3.18 \times 10^{-2} \mathrm{~T}(\mathrm{cal} / \mathrm{kg} \mathrm{K})$

$\mu_{f}=1.662 \times 10^{-6} \mathrm{~T}^{1 / 2}-1.038 \times 10^{-5}(\mathrm{~kg} / \mathrm{m} \mathrm{s})$

$\lambda_{f}=1.27 \times 10^{-4} \mathrm{~T}^{0.7}(\mathrm{cal} / \mathrm{m} \mathrm{s} \mathrm{K})$

$D_{12}=2.094 \times 10^{-9} \mathrm{~T}^{3 / 2}\left(\mathrm{~m}^{2} / \mathrm{s}\right)$

$D_{k}=9.414 r_{m} \mathrm{~T}^{1 / 2}\left(\mathrm{~m}^{2} / \mathrm{s}\right)$

Global heat transfer coefficient

$U=\left[11.5+6.99 \times 10^{-2} c_{p f} u_{0}(\mathrm{PTN})\right] /\left[1.093+5.68 \times 10^{-4} c_{p f} u_{0}(\mathrm{PTN})\right]\left(\mathrm{cal} / \mathrm{m}^{2} \mathrm{~s} \mathrm{~K}\right)$
Catalyst transport properties

$D_{e}=1 /\left(1 / D_{12 e}+1 / D_{k e}\right),\left(\mathrm{m}^{2} / \mathrm{s}\right)$

$D_{12 e}=\varepsilon_{p} D_{12} / \tau_{p}\left(\mathrm{~m}^{2} / \mathrm{s}\right)$

$D_{k e}=\varepsilon_{p} D_{k} / \tau_{p}\left(\mathrm{~m}^{2} / \mathrm{s}\right)$

Film interparticle properties

$k_{f}=j_{D} u_{0} S c^{-2 / 3}(\mathrm{~m} / \mathrm{s})$

$h=j_{D} \rho_{f} u_{0} P r^{-2 / 3}\left(\mathrm{cal} / \mathrm{m}^{2} \mathrm{~s} \mathrm{~K}\right)$

$j_{D}=0.255 R e^{-0.335 / \varepsilon}$ pseudo-homogeneous model, a lumped Péclet number $\left(P e_{a h}=1.9\right)$ was used, Eq. (18) of Table 5, in order to take into account the two contributions of the solid and gas phases according a correlation presented by Dixon (1988) $\left(1 / P e_{a h}=\lambda_{e a}^{s} /\left(\lambda^{f} \operatorname{Re} P r\right)+1 / P e_{a h}^{f}\right)$.

For both kinetic schemes, the steady-state profile obtained in the conventional fixed-bed operation is the starting point for the reverse of the flow direction. The system of partial differential equations was integrated by using the package PDECOL (Madsen and Sincovec, 1975), which implements the method of lines. This code performs the automatic discretization in the space variable $\left(z^{*}\right)$ by the method of orthogonal collocation on finite elements (Carey and Finlayson, 1975). The total spatial domain is divided in finite elements where the exact variables are approximated by using B-splines as trial functions. After the discretization, the resulting system of ordinary differential equations is integrated in time by an implicit integrator included in the package, that is suitable for problems with banded Jacobians. In this work, 50 finite elements were used (100 discretization points), with cubic B-splines as trial functions. The numerical parameters used in the simulation process resulted from a previous study (Quinta Ferreira et al., 1996), where the numerical process was optimised in order to obtain a good compromise between the accuracy of the dynamic response and the computing times.

\section{Computer results}

In this section, the results are presented for each heterogeneous model $\left(\mathrm{HT}_{d c}, \mathrm{HT}_{d}\right)$ and thereafter, two different comparisons are performed: first, the results of these heterogeneous models are compared and secondly the results of both heterogeneous and the simpler pseudohomogeneous model $\mathrm{PH}$ are confronted.

\section{1. $\mathrm{Ht}_{d c}$ model}

Fig. 2 represent the dynamic response of the system, temperature, $o$-xylene and phthalic anhydride concentration gradients in the bulk phase, after reversing the direction of the feed flow for the model which takes into account intraparticle diffusion and convection, $\mathrm{HT}_{d c}$ model with $\lambda_{m}=10$, when $T_{0}=T_{w}=630 \mathrm{~K}$ $\left(p_{0}=0.01 \mathrm{~atm}\right)$. In the following analysis the first kinetic scheme with multiple reactions (Froment, 1967) has been used, unless the contrary is referred. Being the process running in steady-state operation, SSO, with the feed 


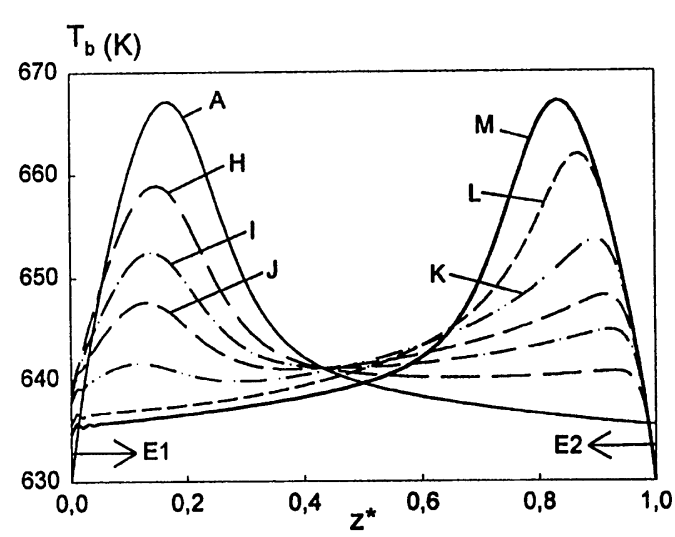

(a)

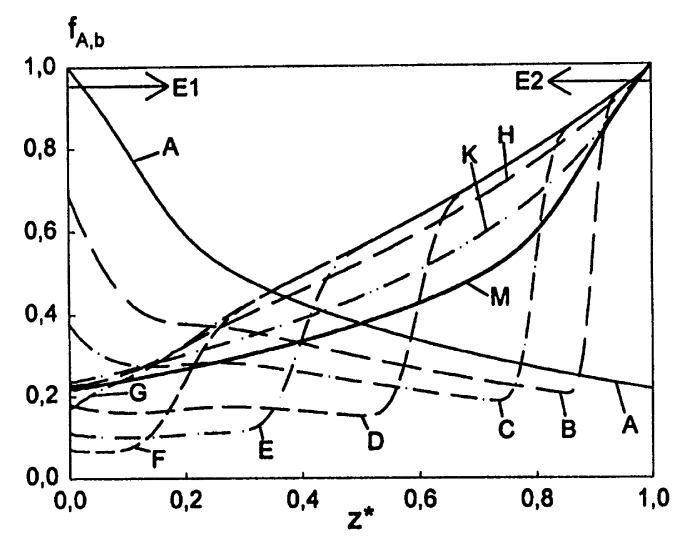

(b)

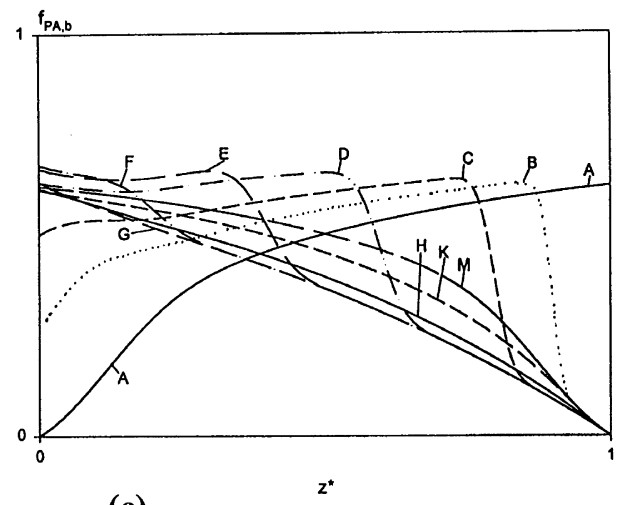

(c)

Fig. 2. Model $\mathrm{HT}_{d c}\left(T_{0}=T_{w}=630 \mathrm{~K}, P_{0}=0.010 \mathrm{~atm}, \lambda_{m}=10\right)$ at steady state (A) and at different dimensionless times, $t^{*}$, after one flow reversal: 0.1 (B), $0.2(\mathrm{C}), 0.4(\mathrm{D}), 0.6(\mathrm{E}), 0.8(\mathrm{~F}), 1.0(\mathrm{G}), 100(\mathrm{H}), 200(\mathrm{I}), 300(\mathrm{~J}), 500(\mathrm{~K}), 1000(\mathrm{~L})$ and $3500(\mathrm{M})$. (a) Fluid temperature; (b) $o$-xylene dimensionless concentration; (c) phthalic anhydride dimensionless concentration. First kinetic scheme.

entering at the entrance $E 1$ and with profiles corresponding to curves $A$, at a time $t^{*}=0$ the direction of the reactional mixture was inverted and the fluid was fed at the opposite end of the tube, E2. Due to the high thermal capacity of the catalytic bed, the velocity of the concentration wave is much higher (about 4800 time higher) than the one of the thermal wave. Therefore, initially the process is isothermal and only the concentration wave travels along the tube, curves $B-G$ in Fig. 2 b. The mass fronts coming from entrance $\mathrm{E} 2$ are propagated along the reactor, but in this case the abrupt decrease of the concentration does not reach zero. Since in the region of the catalytic bed after the fronts (towards outlet $E 1$ ) there is still $o$-xylene from the previous situation, the concentration increases again. During these first times, the temperature profile remains constant, curve $A$. Afterwards, an hot spot develops near the entrance of the fluid mixture $(E 2)$, where the reaction preferentially takes place, and the previous hot spot, near the outlet (E1) decreases, as can be observed through curves $H-L$. Finally, a new steady state will be established with a temperature profile represented by curve $M$, which is symmetrical to the one obtained before the reversal of the flow, curve $A$.
If the flow is reversed again before the final steadystate situation, a cyclic operation will be performed. Fig. 3 show the evolution of the bed temperature, $o$-xylene conversion, yield and selectivity in phthalic anhydride when the fluid flow is reversed periodically by feeding the reactional mixture alternatively in $E 1$ or $E 2$, after short intervals of time $\left(t_{\mathrm{inv}}^{*}=60 ; t_{\mathrm{inv}}=33 \mathrm{~s}\right)$. Curves 0 are the profiles corresponding to curves $A$ of Fig. 2, i.e., the steady-state situation before the first flow reversal. Curves 1 are the profiles obtained after a time $t_{\text {inv }}^{*}=60$ when the feed is entering in E2. At this time, the flux is reversed again, entering now through $E 1$, and after the same time interval, $t_{\mathrm{inv}}^{*}=60$, the profiles are represented by curves 2 . Curves 5 and 6 represent the profiles after five and six inversions (fluid entering, respectively, in $E 1$ and E2). One can observe that after these reversals in the region near the extremity of the tube $E 1$, where the steady state hot spot was initially developed, the maximum temperatures decrease while in the opposite zone, close to $E 2$, the catalytic bed is being heated. After some time (approximately 12 cycles, or 24 inversions), a stable situation is attained. In fact, maintaining the cyclic operation afterwards, there will be always the same two types of 

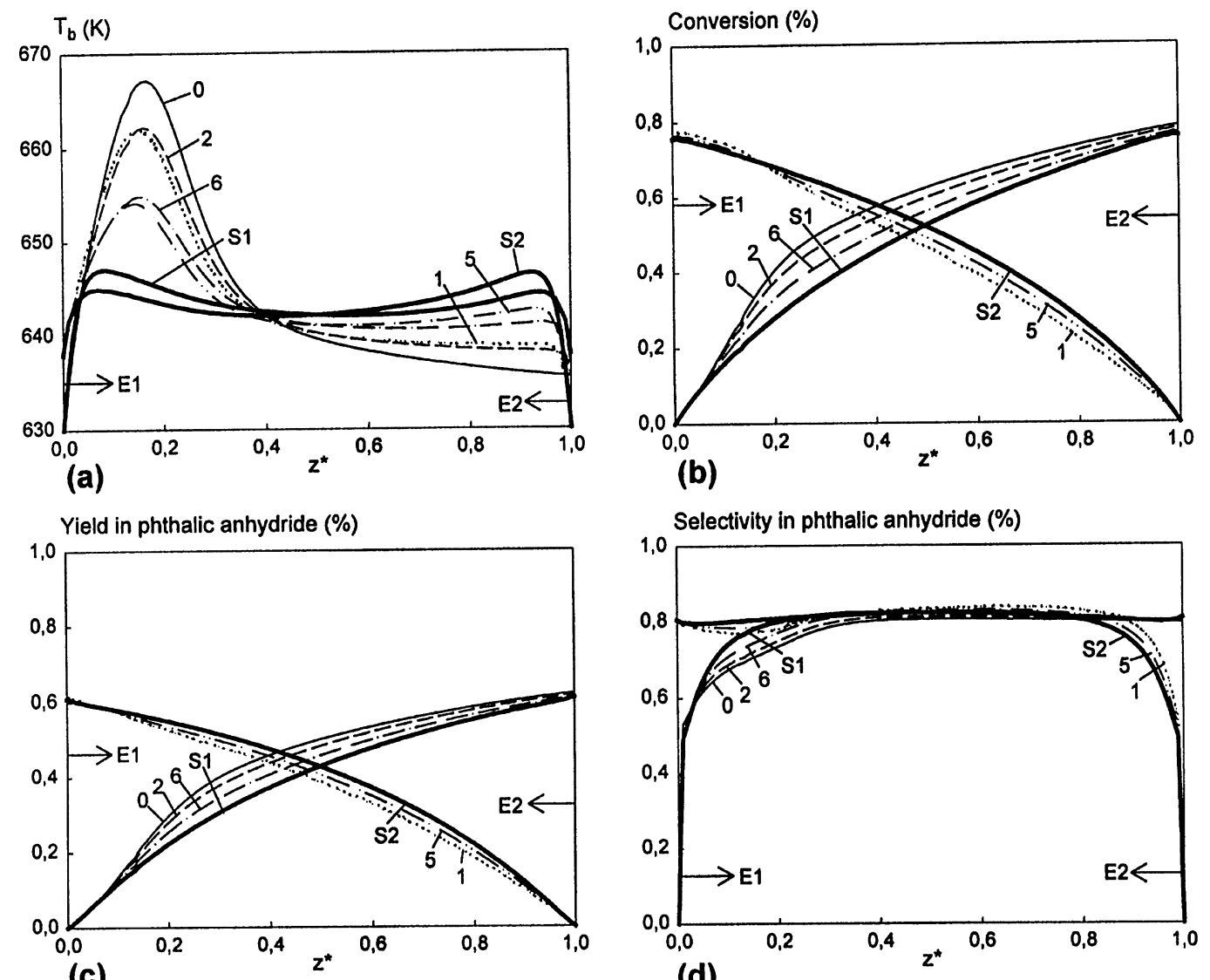

(b)

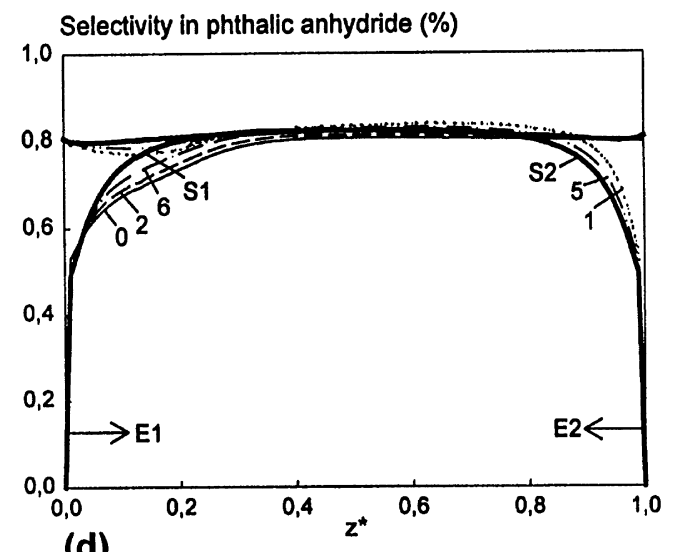

(d)

Fig. 3. Model $\mathrm{HT}_{d c}\left(T_{0}=T_{w}=630 \mathrm{~K}, P_{0}=0.010 \mathrm{~atm}, \lambda_{m}=10, t_{i n v}^{*}=60\right)$ at steady state (0), after 1, 2, 5, 6 flow reversals and at pseudo-steady state ( $S 1$ when the fluid enters in $E 1$ and $S 2$ when it enters in E2). Axial profiles of: (a) fluid temperature; (b) conversion; (c) yield; (d) selectivity in phthalic anhydride. First kinetic scheme.

symmetrical final profiles: $S 1$, if the fluid enters through $E 1$, and $S 2$, if the fluid is fed in E2. We designed this behaviour as a pseudo-steady state, though the process is operating under transient conditions. Regarding to the thermal effects, one can observe in Fig. 3a the significant gain that can be predicted. The temperature profiles have now been flattened with a significant decrease on the hot spot, when compared to the one corresponding to the unidirectional operation (curve 0 ). And though this corresponds to a small decrease in the final $o$-xylene conversion and phthalic anhydride yield, a slight increase in the selectivity can be observed, by comparing curves 0 with curves $S 1$ and $S 2$ at $E 1$ and E2, in Fig. $3 b$, c and d, respectively. Therefore, the cyclic operation can allow a similar performance of the system, involving a lower deactivation of the catalyst. This is so, because it makes use of the reactive potential of the overall catalytic bed, contrarily to the unidirectional operation, which concentrates the reactive process mainly near the entrance of the reactant flux.

Fig. 4 show a comparison of the final results which are obtained when different inversion times were used, $t_{\mathrm{inv}}^{*}=60,120$ and $240\left(t_{\mathrm{inv}}=33 \mathrm{~s} ; 66 \mathrm{~s} ; 132 \mathrm{~s}\right)$. In all cases a significant reduction in the maximum temperature can be obtained if one compares the pseudo-steady state of the reversal flow operation, RFO, with the steady-state operation, SSO, Fig. 4a. As expected, this gain is lower when the cycle time increases, since using higher intervals of time for reversing the flow, higher temperatures will be developed approaching those corresponding to the steady-state behaviour. A slight increase of selectivity, Fig. 4d, and some decrease on conversion, Fig. 4b, and yield, Fig. $4 \mathrm{c}$ are observed. However, the most important point which must be emphasised is that the substantial reductions in the bed temperatures do not affect significantly conversion, yield and selectivity.

\section{2. $\mathrm{Ht}_{d}$ model}

For the model which considers diffusion as the exclusive mechanism of transport inside the catalyst particles, $\mathrm{HT}_{d}$ model, the behaviour of the system under reverse flow operation is similar. However, in this case the reactant conversion is lower and, therefore, in order to have 


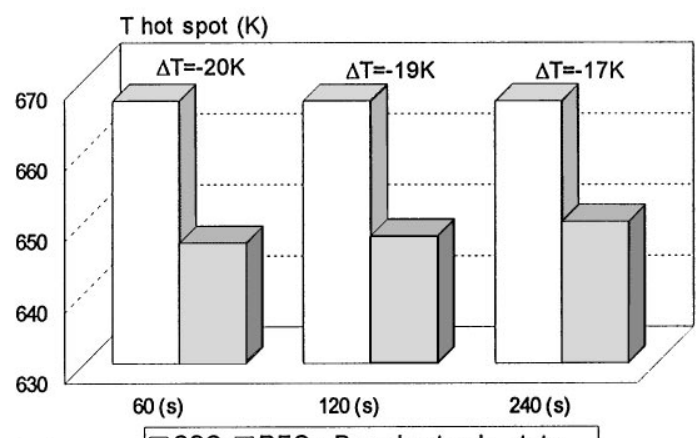

(a)

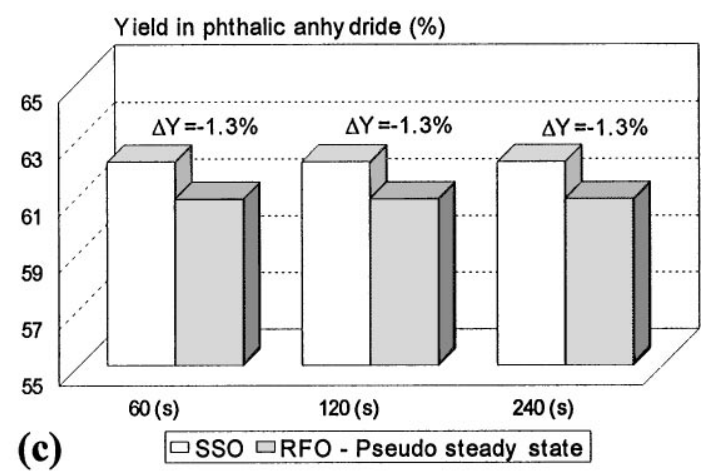

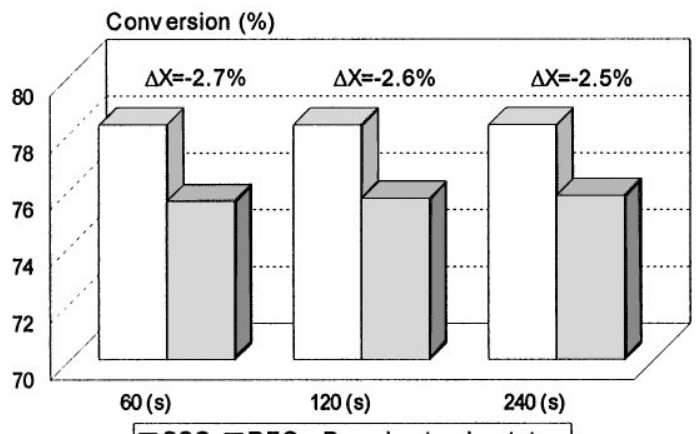

(b)

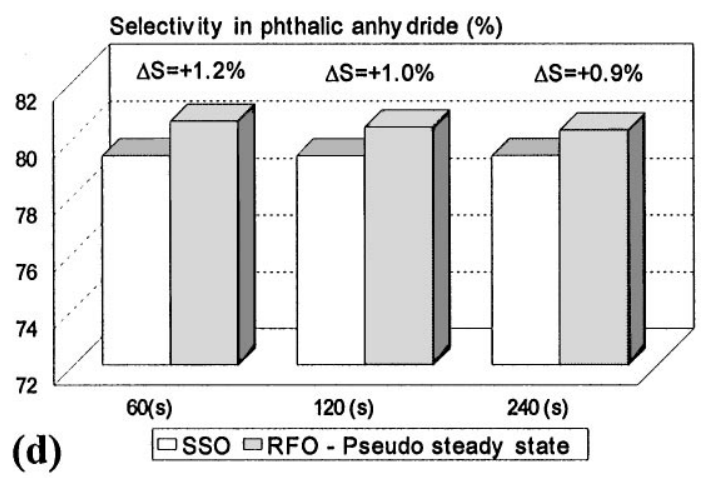

Fig. 4. Model $\mathrm{HT}_{d c}\left(T_{0}=T_{w}=630 \mathrm{~K}, P_{0}=0.010 \mathrm{~atm}, \lambda_{m}=10\right)$ with $t_{\mathrm{inv}}^{*}=60,120$ and 240, at steady-state operation (SSO) and pseudo-steady state of reverse flow operation (RFO). (a) Hot spot temperature; (b) conversion; (c) yield; (d) selectivity in phthalic anhydride. First kinetic scheme.

final conditions close to the ones obtained with the $\mathrm{HT}_{d c}$ model the results presented in Fig. 5 were obtained with a higher inlet temperature, $T_{0}=T_{w}=640 \mathrm{~K}$. Departing from a steady-state profile with high hot spot (curve 0), and using the same interval of time of $t_{\mathrm{inv}}^{*}=60$ as before, curves 1 and 5 represent the profiles obtained when the fluid enters $E 2$, after one and five inversions, respectively. The profiles corresponding to the entrance in $E 1$ are curves 2 and 6 obtained after two and six flow reversals. The final pseudo-steady-state profiles, $S 1$ (when the fluid enters through E1), or $S 2$ (when it enters in E2), show the spread of the temperature along all the catalytic bed in Fig. 5a. Thus, significant reduction in the deactivation process of the catalyst is also expected in this case. The same trend as for the previous model is found in the other parameters, conversion, yield and selectivity, Fig. 5b-d.

\subsection{Comparison of $\mathrm{Ht}_{d c}$ and $\mathrm{Ht}_{d}$ models}

Fig. 6 compare the final results of these two models in different situations: model $\mathrm{HT}_{d}$ with $T_{0}=640 \mathrm{~K}$ and $630 \mathrm{~K}$ and model $\mathrm{HT}_{d c}$ with $T_{0}=640 \mathrm{~K}$. For the first model, $\mathrm{HT}_{d}$, a higher inlet temperature will lead to higher values of the hot-spot, conversion and yield, and also a significant reduction of the selectivity. For the same inlet temperatures, $T_{0}=630 \mathrm{~K}$, the hot spot of the $\mathrm{HT}_{d c}$ model is higher than for the $\mathrm{HT}_{d}$ model, Fig. 6a, since the reaction rates increase with the higher amount of reactant entering inside the catalyst due to the additional convective mechanism. This also leads to higher conversions and yields, Fig. 6b,c, while the selectivity is approximately the same, Fig. 6d. Comparing now the results when both models have the same conversion, Fig. 6b, one observes in Fig. 6a that the hot spot of the $\mathrm{HT}_{d c}$ model (with $T_{0}=630 \mathrm{~K}$ ) is lower, and the gain in the maximum temperature using cyclic operation is higher than for the $\mathrm{HT}_{d}$ model (with $T_{0}=640 \mathrm{~K}$ ). Moreover, the yield and selectivity are also higher when intraparticle convection is taken into account, Fig. $6 \mathrm{c}$ and d. These results show that using large pore catalysts, where the convective mechanism is promoted, lower inlet and wall temperatures can be used and lower maximum temperatures are developed in the catalytic bed leading also to a lower deactivation of the catalyst. Therefore, savings in operating costs can be expected.

\subsection{Comparison of $\mathrm{Ht}_{d c}, \mathrm{Ht}_{d}$ and $\mathrm{PH}$ models}

We have also used a more simplified model, the pseudo-homogeneous model, $\mathrm{PH}$, which neglects all the inter and intraparticle resistances. However, for the operating conditions we used before, this model presented a very high thermal sensitivity with runaway behaviour, 

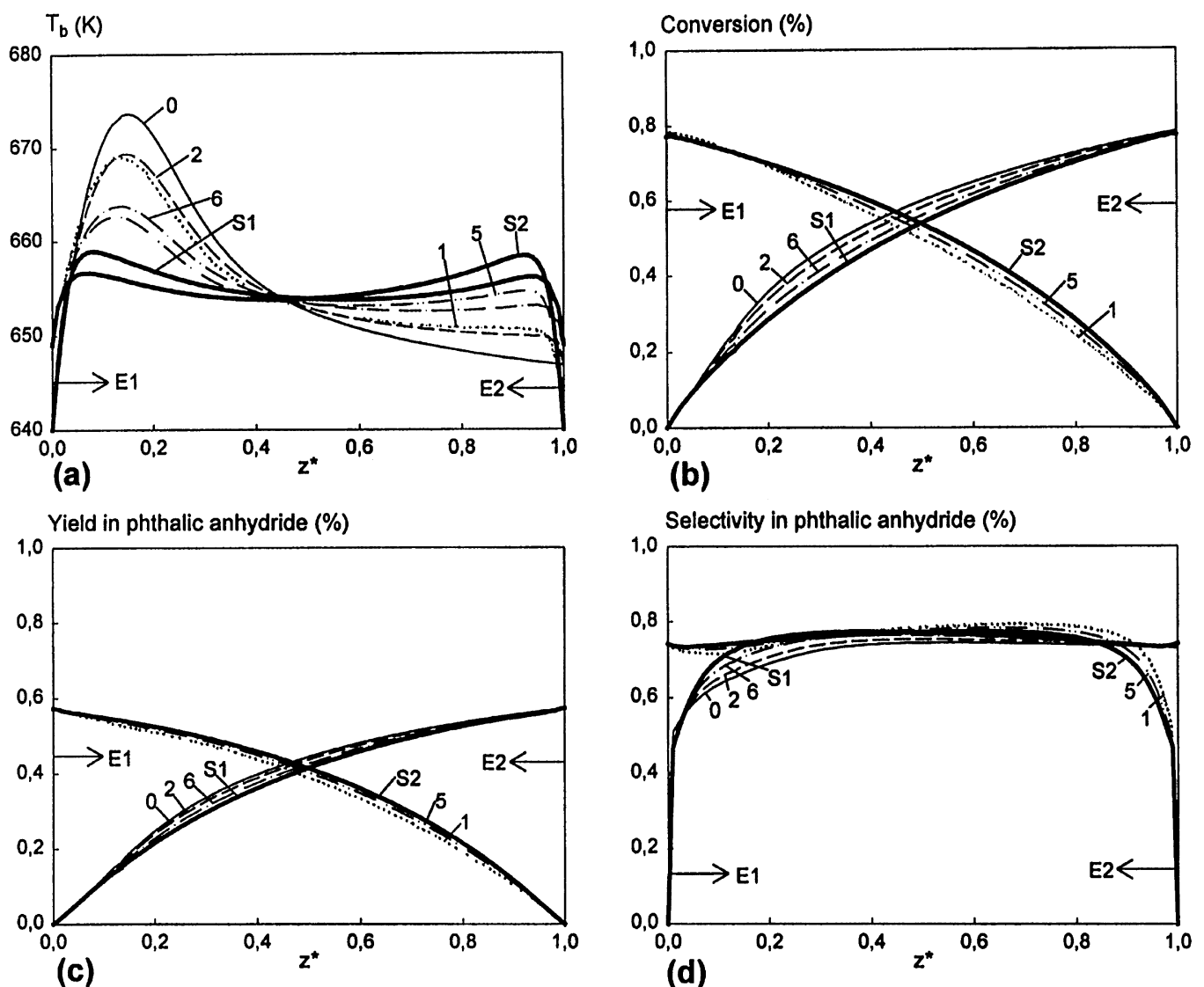

Fig. 5. Model $\operatorname{HT}_{d}\left(T_{0}=T_{w}=640 \mathrm{~K}, P_{0}=0.010 \mathrm{~atm}, \lambda_{m}=0, t_{\text {inv }}^{*}=60\right)$ at steady state $(0)$, after 1, 2, 5, 6 flow reversals and at pseudo-steady state $(S 1$ when the fluid enters in $E 1$ and $S 2$ when it enters in E2). Axial profiles of: (a) fluid temperature; (b) conversion; (c) yield; (d) selectivity in phthalic anhydride. First kinetic scheme.

attaining extremely high temperatures. Using a more simplified kinetic scheme, assuming a pseudo-first-order reaction, one could compare the results obtained with the heterogeneous models with those predicted by the $\mathrm{PH}$ model. For this second kinetic scheme, Fig. 7 show the comparison between the three models, $\mathrm{HT}_{d}, \mathrm{HT}_{d c}$ and PH models when $T_{0}=T w=625 \mathrm{~K}\left(p_{0}=0.017 \mathrm{~atm}\right)$. The $\mathrm{HT}_{d c}$ model predicts higher temperatures and conversions and under cyclic operation an higher decrease in the hot spot is observed, which also leads to a small decrease in the final conversion. For these operating conditions the results of the pseudo-homogeneous model are closer to those of the $\mathrm{HT}_{d c}$ model than the ones obtained with the $\mathrm{HT}_{d}$ model. However, for higher inlet temperatures, $T_{0}=T w=660 \mathrm{~K}$, Fig. 8, the $\mathrm{PH}$ model reveals a runaway behaviour, showing once more that it will not be adequate to the analysis of such exothermic processes. For these feed temperatures the gain in the maximum temperatures are very high when reverse flow operation is used, in particular for the $\mathrm{HT}_{d c}$ model, though a slight decrease in conversion can be detected. The significant differences in the behaviour of the system, when periodic reversing of the feed flow is assumed are shown in Fig. 9, which confirms that a similar performance of the system can be obtained by forcing an effective utilisation of all the catalytic bed. In fact, in these conditions, the process will take place under less severe circumstances, with not so high reactions rates, as the ones which are required when only a small fraction of the catalyst is encharged of the reactional process. As a consequence, much lower temperatures are developed, curves $S 1$ and $S 2$ in Fig. 9a, for getting almost the same final conversion, Fig. 9b. This will be accomplished with an overall increase of the effectiveness factors of the catalyst particles, Fig. 9c, as a consequence of a decrease of the Thiele modulus, Fig. 9d.

\section{Conclusions}

The cyclic operation of a system when an highly exothermic reaction is taking place can be advantageous to overcome some thermal shortcomings mainly associated to the development of high internal temperatures which can lead to a rapid catalyst deactivation. In fact, reversing the fluid flow and forcing its entrance through 

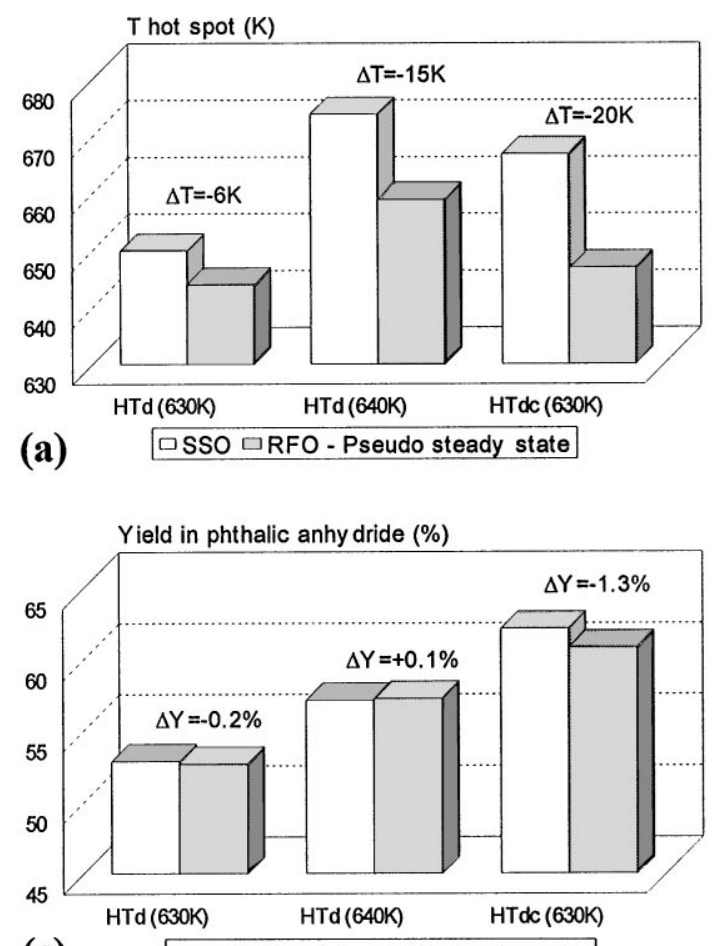

(c)

口SSO $\square$ RFO - Pseudo steady state

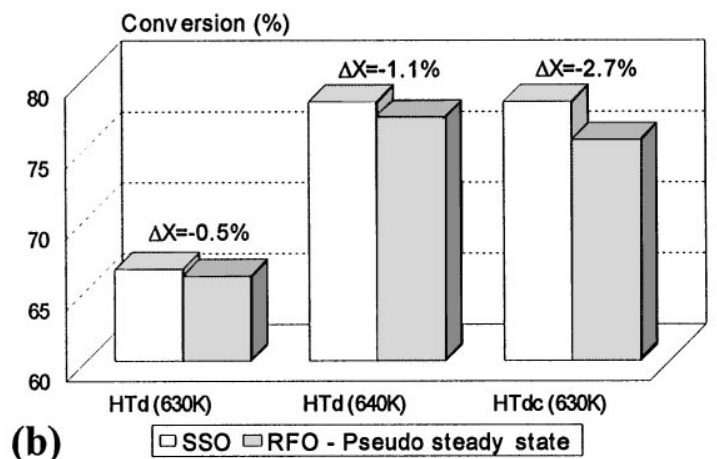

Selectivity in phthalic anhy dride (\%)

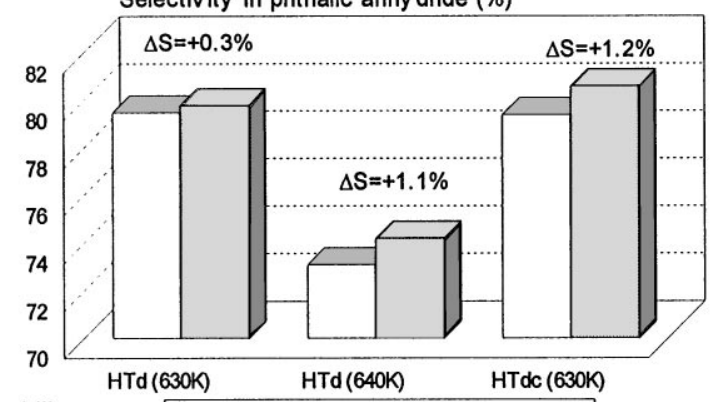

(d)

$\square$ SSO $\square$ RFO - Pseudo steady state

Fig. 6. Models $\operatorname{HT}_{d}\left(T_{0}=T_{w}=630 \mathrm{~K}\right.$ and $\left.T_{0}=T_{w}=640 \mathrm{~K}\right)$ and $\mathrm{HT}_{d c}\left(T_{0}=T_{w}=630 \mathrm{~K}, \lambda_{m}=10\right)$ at steady-state operation (SSO) and pseudosteady state of reverse flow operation (RFO) $\left(P_{0}=0.010 \mathrm{~atm}, t_{\mathrm{inv}}^{*}=60\right)$. (a) Hot spot temperature; (b) conversion; (c) yield; and (d) selectivity in phthalic anhydride. First kinetic scheme.
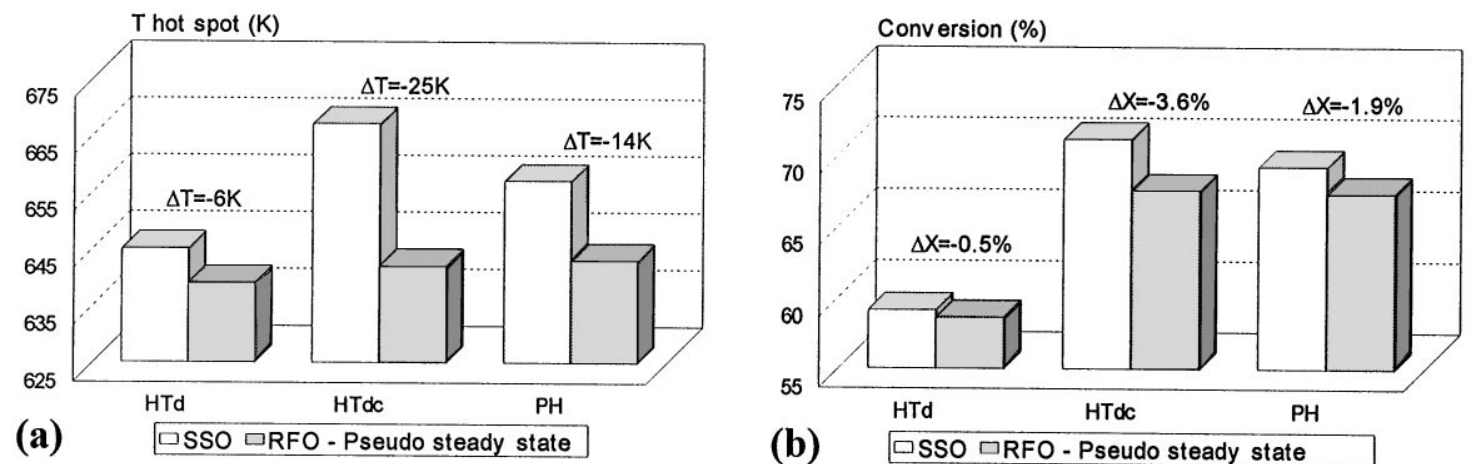

Fig. 7. Models $\mathrm{HT}_{d}, \mathrm{HT}_{d c}\left(\lambda_{m}=10\right)$ and $\mathrm{PH}$ at steady operation (SSO) and pseudo-steady state of reverse flow operation $(\mathrm{RFO})\left(T_{0}=T_{w}=625 \mathrm{~K}\right.$, $P_{0}=0.017$ atm, $t_{\text {inv }}^{*}=60$ ). (a) Hot spot temperature; (b) conversion. Second kinetic scheme.

both ends of the tubular reactor alternatively, all the catalytic bed will be involved in the reactive process. Therefore, the same performance of the system, in terms of conversion, yield and selectivity can be achieved with less severe hot spots. In fact, a significant reduction of the maximum can be obtained by working with a more uniform temperature profile along the bed.

The simulation studies were performed with two heterogeneous models for the partial oxidation of $o$-xylene to phthalic anhydride, the conventional model accounting for diffusion as the only transport mechanism inside the catalyst, $\mathrm{HT}_{d}$ model, and the heterogeneous model considering both intraparticle diffusion and convection, $\mathrm{HT}_{d c}$ model. Also under reverse flow operation the advantages of using large pore catalyst has been highlighted. Higher conversions, yields and selectivities and also higher gains in temperature reductions under cyclic operation were observed for the $\mathrm{HT}_{d c}$ model when compared with the $\mathrm{HT}_{d}$ model. Our results also pointed out that the simple pseudo-homogeneous model, $\mathrm{PH}$, is not appropriate to describe the behaviour of the system. 


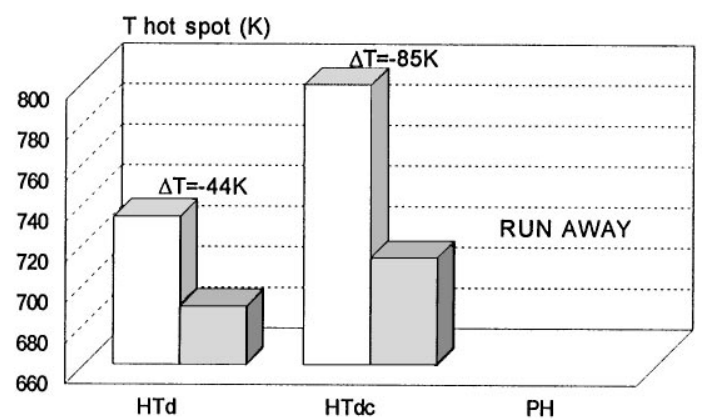

(a)

QSSO $\square$ RFO - Pseudo steady state

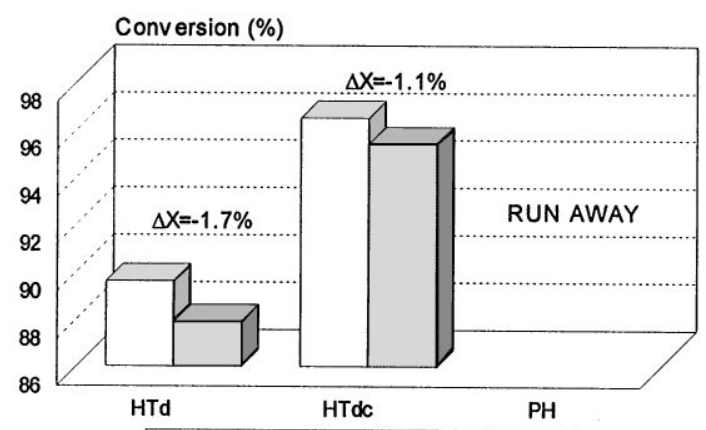

(b)

$\square$ SSO $\square R F O$ - Pseudo steady state

Fig. 8. Models $\mathrm{HT}_{d}, \mathrm{HT}_{d c}\left(\lambda_{m}=10\right)$ and $\mathrm{PH}$ at steady-state operation (SSO) and pseudo-steady state of reverse flow operation (RFO) $\left(T_{0}=T_{w}=660 \mathrm{~K}, P_{0}=0.017 \mathrm{~atm}, t_{\mathrm{inv}}^{*}=60\right)$. (a) Hot spot temperature; (b) conversion. Second kinetic scheme.

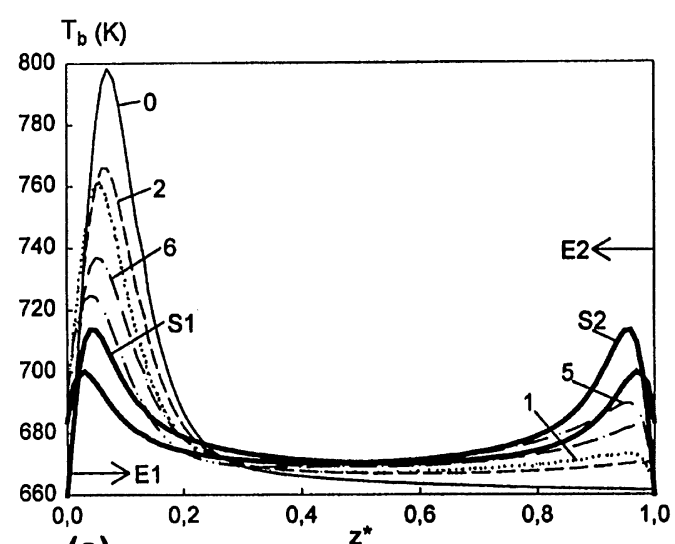

(a)

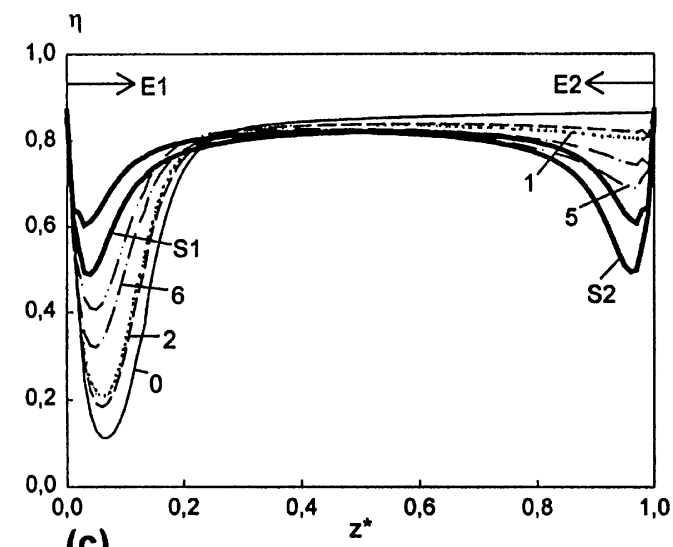

(c)

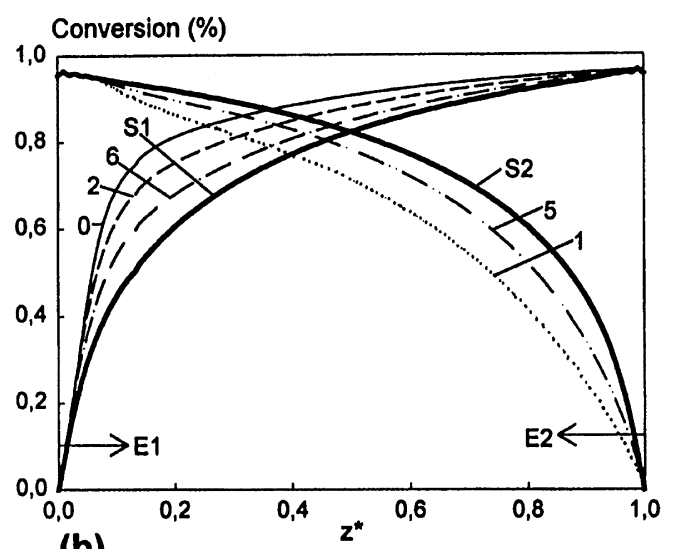

(b)

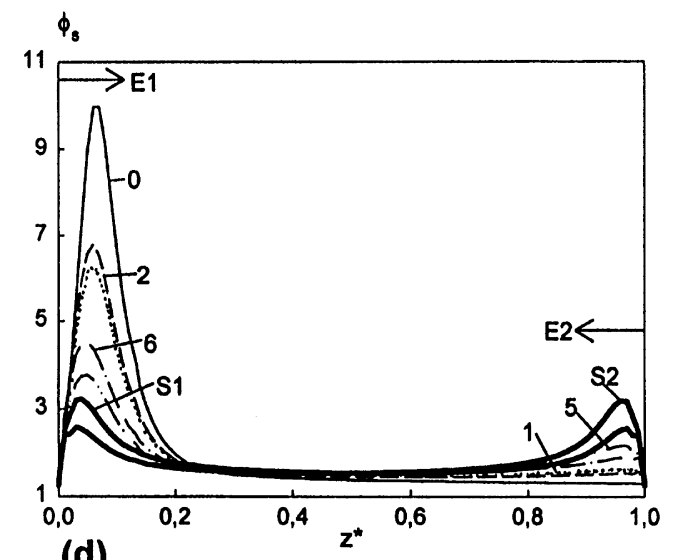

(d)

Fig. 9. Model $\mathrm{HT}_{d c}\left(T_{0}=T_{w}=660 \mathrm{~K}, P_{0}=0.017 \mathrm{~atm}, \lambda_{m}=10, t_{\mathrm{inv}}^{*}=60\right)$ at steady state $(0)$, after 1,2,5,6 flow reversals and at pseudo-steady state ( $S 1$ when the fluid enters in $E 1$ and $S 2$ when it enters in E2). Axial profiles of: (a) fluid temperature; (b) conversion; (c) effectiveness factor; (d) Thiele modulus. Second kinetic scheme.

\section{Notation}

$a_{p} \quad$ specific particle area, $\mathrm{m}^{-1}$

$B$ dimensionless adiabatic temperature rise, $B=(-\Delta H) C_{0} / T_{0} \rho_{f} c_{p f}$

$B_{j} \quad$ dimensionless adiabatic temperature rise of reaction $j, B_{j}=\left(-\Delta H_{j}\right) C_{0} / T_{0} \rho_{f} c_{p f}$
$B i_{m} \quad$ Mass Biot number, $B i_{m}=k_{f} R_{p} / D_{e}$

$c_{p f} \quad$ heat capacity of the fluid, cal $/ \mathrm{kg} \mathrm{K}$

$c_{p s} \quad$ heat capacity of the catalyst, cal $/ \mathrm{kg} \mathrm{K}$

$C$ reactant concentration, $\mathrm{mol} / \mathrm{m}^{3}$

$C_{i} \quad$ concentration of species $i, \mathrm{~mol} / \mathrm{m}^{3}$

$C_{0} \quad$ reactant concentration in the feed, $\mathrm{mol} / \mathrm{m}^{3}$

$d_{p} \quad$ equivalent diameter of the particle, $\mathrm{m}$ 
Da Damkhöler number, $D a=k\left(T_{0}\right) \tau / \varepsilon$

$D a_{j} \quad$ Damkhöler number of reaction $j, D a_{j}=$ $k_{j}\left(T_{0}\right) \tau / \varepsilon$

$D_{12}$ molecular diffusivity, $\mathrm{m}^{2} / \mathrm{s}$

$D_{12 e} \quad$ effective molecular diffusivity, $\mathrm{m}^{2} / \mathrm{s}$

$D_{e} \quad$ effective diffusivity, $\mathrm{m}^{2} / \mathrm{s}$

$D_{e a} \quad$ axial effective diffusivity, $\mathrm{m}^{2} / \mathrm{s}$

$D_{k e} \quad$ effective Knudsen diffusivity, $\mathrm{m}^{2} / \mathrm{s}$

$D_{k} \quad$ Knudsen diffusivity, $\mathrm{m}^{2} / \mathrm{s}$

E activation energy, $\mathrm{cal} / \mathrm{mol}$

$E_{j} \quad$ activation energy of reaction $j, \mathrm{cal} / \mathrm{mol}$

$f$ dimensionless reactant concentration, $f=C / C_{0}$

$f_{i}$ dimensionless concentration of species $i, f_{i}=$ $C_{i} / C_{0}$

$h \quad$ film heat transfer coefficient, $\mathrm{cal} / \mathrm{m}^{2} \mathrm{~s} \mathrm{~K}$

$\Delta H \quad$ heat of reaction, $\mathrm{cal} / \mathrm{mol}$

$\Delta H_{j} \quad$ heat of reaction $j, \mathrm{cal} / \mathrm{mol}$

$k \quad$ reaction kinetic constant, $\mathrm{s}^{-1}$

$k_{f} \quad$ film mass transfer coefficient, $\mathrm{m} / \mathrm{s}$

$k_{j} \quad$ kinetic constant of reaction $j, \mathrm{~s}^{-1}$

$L \quad$ reactor length, $m$

$N_{d} \quad$ number of pore diffusion units, $N_{d}=D_{e} \tau / \varepsilon_{p} R_{p}^{2}$

$N_{f} \quad$ number of film mass transfer units,

$N_{f}=(1-\varepsilon) k_{f} a_{p} \tau / \varepsilon$

$N_{f h} \quad$ number of film heat transfer units,

$N_{f h}=(1-\varepsilon) h a_{p} \tau / \varepsilon \rho_{f} c_{p f}$

$N_{w h}$ number of wall heat transfer units, $N_{w h}=$ $2 U \tau / \varepsilon R_{0} \rho_{f} c_{p f}$

$P \quad$ pressure, atm

$P_{0} \quad O$-Xylene partial pressure at the reactor entrance, atm

$P_{\mathrm{O}_{2}}^{0} \quad$ oxygen partial pressure at the reactor entrance, atm

$P e_{a h} \quad$ axial thermal Peclet number based on the reactor length, $P e_{a h} L u_{0} \rho_{f} c_{p f} / \lambda_{e a}$

$P e_{a m} \quad$ axial mass Peclet number based on the reactor length, $P e_{a m}=L u_{0} / D_{e a}$

$\operatorname{Pr} \quad$ Prandtl number, $\operatorname{Pr}=c_{p f} \mu_{f} / \lambda_{f}$

$r_{m} \quad$ average porous radius, $\mathrm{m}$

$r_{p} \quad$ spatial coordinate in the particle, $\mathrm{m}$

$r_{p}^{*} \quad$ dimensionless particle coordinate, $r_{p}^{*}=r_{p} / 2 R_{p}$

$R \quad$ ideal gas constant

$R_{0} \quad$ reactor radius, $\mathrm{m}$

Re Reynold number, $R e=\rho_{f} u_{0} d_{p} / \mu_{f}$

$R_{p} \quad$ half thickness of the slab catalyst, $\mathrm{m}$

$S_{\text {BET }} \quad$ surface area, $\mathrm{m}^{2} / \mathrm{g}$

$S c$

$S_{j}$

$t$

$t^{*}$

$t_{\text {inv }}$

$t_{\text {inv }}^{*}$

$T$

$T_{0}$

$T_{w}$

$u_{0}$

feed temperature, $\mathrm{K}$

wall temperature, $\mathrm{K}$

superficial velocity, $\mathrm{m} / \mathrm{s}$ $u \quad$ interstitial velocity $(\mathrm{m} / \mathrm{s}), u=u_{0} / \varepsilon$

$U$ global wall heat transfer coefficient, cal $/ \mathrm{m}^{2} \mathrm{~s} \mathrm{~K}$

$v_{0} \quad$ intraparticle fluid velocity, $\mathrm{m} / \mathrm{s}$

$z \quad$ reactor axial coordinate, $\mathrm{m}$

$z^{*} \quad$ dimensionless reactor axial coordinate, $z^{*}=z / L$

\section{Greek letters}

$\alpha \quad$ coefficients defined in Table 5

$\gamma \quad$ Arrhenius number, $\gamma=E / R T_{0}$

$\gamma_{j} \quad$ Arrhenius number of reaction $j, \gamma_{j}=E_{j} / R T_{0}$

$\varepsilon \quad$ bulk porosity

$\varepsilon_{p} \quad$ catalyst porosity

$\eta \quad$ effectiveness factor referred to the catalyst surface

$\eta_{j} \quad$ effectiveness factor of reaction $j$ referred to the catalyst surface

$\theta \quad$ dimensionless temperature, $\theta=T / T_{0}$

$\lambda_{f} \quad$ fluid thermal conductivity, cal $/ \mathrm{m} \mathrm{s} \mathrm{K}$

$\lambda_{e a} \quad$ axial effective thermal conductivity, cal $/ \mathrm{m} \mathrm{s} \mathrm{K}$

$\lambda_{m} \quad$ intraparticle mass Peclet number, $\lambda_{m}=v_{0} R_{p} / D_{e}$

$\mu_{f} \quad$ fluid viscosity, $\mathrm{kg} / \mathrm{m} \mathrm{s}$

$\rho_{f} \quad$ fluid density, $\mathrm{kg} / \mathrm{m}^{3}$

$\rho c_{p} \quad$ average bed heat capacity $\left(\mathrm{cal} / \mathrm{m}^{3} \mathrm{~K}\right)$, $\rho c_{p}=\varepsilon \rho_{f} c_{p f}+(1-\varepsilon) \rho_{s} c_{p s}$

$\rho_{s} c_{p s} \quad$ average particle heat capacity, cal $/ \mathrm{m}^{3} \mathrm{~K}$

$\tau \quad$ space time for the fluid, $\tau=L / u$

$\tau_{h} \quad$ space time for the thermal wave for the HT's model, $\tau_{h}=(1-\varepsilon) \rho_{s} c_{p s} \tau / \varepsilon \rho_{f} c_{p f}$

$\tau_{h l} \quad$ space time for the thermal wave for the $\mathrm{PH}$ model, $\tau_{h l}=(1-\varepsilon) \rho c_{p} \tau / \varepsilon \rho_{f} c_{p f}$

$\tau_{p} \quad$ tortuosity factor

$\Phi_{s} \quad$ Thiele modulus, $\Phi_{s}=R_{p}\left[k\left(\theta_{s}\right) /(1-\varepsilon) D e\left(\theta_{s}\right)\right]^{1 / 2}$

$\Phi_{s, j} \quad$ Thiele modulus of reaction

$j, \Phi_{s, j}=R_{p}\left[k_{j}\left(\theta_{s}\right) /(1-\varepsilon) D e\left(\theta_{s}\right)\right]^{1 / 2}$

\section{Subscripts}

1 reaction from $o$-xylene to phthalic anhydride

2 reaction from phthalic anhydride to carbon oxides

3 reaction from $o$-xylene to carbon oxides

$A \quad O$-Xylene

$b \quad$ bulk condition in the fluid phase

$B \quad$ phthalic anhydride

d diffusion

$d c \quad$ diffusion/convection

$i \quad$ chemical species, $i=\mathrm{A}$ or $\mathrm{B}$

$j \quad$ reaction, $j=1,2$, or 3

$s$ particle surface

$p \quad$ particle

w wall

\section{Superscripts}

$f \quad$ fluid

$s \quad$ solid 


\section{References}

Almeida Costa, C., Quinta Ferreira, R. M., \& Rodrigues, A. E. (1994). Wrong-way behaviour in fixed-bed reactors with large-pore catalysts. Chemical Engineering Science, 49, 5571-5583.

Carey, G., \& Finlayson, B. (1975). Orthogonal collocation on finite elements. Chemical Engineering Science, 30, 587-596.

Dixon, A. G. (1988). Wall and particle-shape effects on heat transfer in packed beds. Chemical Engineering Communication, 71, 217-237.

Eingenberger, G., \& Nieken, U. (1988). Catalytic combustion with periodic flow reversal. Chemical Engineering Science, 43, 3023-3030.

Froment, G. F. (1967). Fixed-bed catalytic reactors. Industrial and Engineerig Chemistry, 59, 18-27.

Froment, G. F., \& Bischoff, K. (1979). Chemical Reactor Analysis and Design. New York, USA: Wiley.

Gawdzik, A., \& Rakowski, L. (1988). Dynamic properties of the adiabatic tubular reactor with switch flow. Chemical Engineering Science, 43, 3023-3030.

Gosiewski, K., \& Sztaba, R. (1990). In Yy. Sh. Matros, Unsteady State Processes in Catalysis. (pp. 629-635). VPS BV, Utrecht.

Madsen, N., \& Sincovec, R. (1975). PDECOL: General collocation on finite elements. Chemical Engineering Science, 30, 587-596.

Matros, Y. S. (1990). Performance of catalytic processes under unsteady conditions. Chemical Engineering Science, 45, 2097-2102.

Matros, Y., \& Bunimovich, G. A. (1996). Reverse-flow operation in fixed bed catalytic reactors. Catalysis Review - Science and Engineering, 38, 1-68.

Nieken, U., Kolios, G., \& Eigenberger, G. (1995). Limiting cases and approximate solutions for fixed-bed reactors with periodic flow reversal. The American Institute of Chemical Engineers Journal, 41, 1915-1925.
Quinta Ferreira, R. M., Costa, A. C., \& Rodrigues, A. E. (1992a). Dynamic behaviour of fixed-bed reactors with large-pore catalysts: a bidimensional heterogeneous diffusion/convection model. Computation in Chemical Engineering, 16, 721-751.

Quinta Ferreira, R. M., Marques, M. M., Babo, M. F., \& Rodrigues, A. E. (1992b). Modelling of the methane steam reforming reactor with large-pore catalysts. Chemical Engineering Science, 47, 2909-2914.

Quinta Ferreira, R. M., Costa, A. C., \& Rodrigues, A. E. (1996). Effect of intraparticle convection on the transient behaviour of fixed-bed reactors: finite differences and collocation methods for solving unidimensional models. Computation in Chemical Engineering, 20, 1201-1225.

Rehacek, J., Kubicek, M., \& Marek, M. (1992). Modelling of a tubular catalytic reactor with flow reversal. Chemical Engineering Science, 47, 2897-2902.

Rodrigues, A. E., \& Quinta Ferreira, R. M. (1990). Effect of intraparticle convection on the steady-state behaviour of fixed-bed catalytic reactors. Chemical Engineering Science, 45, 2653-2660.

Snyder, J. D., \& Subramanian, B. (1993). Numerical simulation of a periodic flow reversal reactor for sulfur dioxide oxidation. Chemical Engineering Science, 48, 4051-4064.

Thullie, J. \& Burghardt, A. (1990). In Yy. Sh. Matros, Unsteady State Processes in Catalysis (pp. 687-692). VPS BV, Utrecht.

Van den Bussche, K. M., Neophytides, S. N., Zolotarski, I. A., \& Froment, G. F. (1993). Modeling and simulation of the reversed-flow operation of a fixed-bed reactor for methanol synthesis. Chemical Engineering Science, 48, 3335-3345.

Windes, L., Schwedock, M., \& Harmon Ray, W. (1989). Steady state and dynamic modeling of a packed-bed reactor for the partial oxidation of methanol to formaldehyde: I. Model development. Chemical Engineering Communication, 78, 1-43. 